\title{
A curriculum for students with intellectual disabilities in Jordan
}

\author{
Eman Al-Zboon ${ }^{1}$ \\ ${ }^{1}$ Special Education Department, Queen Rania Faculty for Childhood, Hashemite University, Jordan
}

\footnotetext{
HOW TO CITE:

Al-Zboon, E.K. (2021).

A curriculum for students

with intellectual disabilities

in Jordan. International Journal

of Special Education,

36(1), 59-68

CORRESPONDING AUTHOR:

Eman K. Al-Zboon;

Emank@hu.edu.jo

DOI:

https://doi.org/10.52291/

ijse.2021.36.6

\section{COPYRIGHT STATEMENT:}

Copyright: (C) 2021 Authors.

Open access publication under the terms and conditions of the Creative Commons

Attribution (CC BY)

license (http://creativecommons.

org/licenses/by/4.0/).
}

\begin{abstract}
This qualitative study describes the status of the curriculum for students with intellectual disabilities (SWID) in Jordan, from their teachers' perspectives and from field observations. Research data were analysed using content analysis methodology. These qualitative data were gained by interviews with 54 teachers and by field observations of classes of SWID. Data analysis revealed five major themes: teachers' perceptions of curriculum areas, teachers' perceptions of curriculum characteristics, levels of teacher professional competence and training needs and teachers' perceptions of problems of curriculum implementation and curriculum components. The study concludes that there is widespread confusion regarding the curriculum for SWID; genuine problems in access to the general curriculum for SWID; problems in SWID preparation for inclusion; and low expectations regarding SWID. Recommendations are provided regarding the importance of enhancing the SWID curriculum, and of improving teachers' professionalism and practices.
\end{abstract}

Keywords: curriculum; intellectual disabilities; special education; teachers 


\section{INTRODUCTION}

Intellectual disability (ID) is considered a neurodevelopmental disorder which limits the learning abilities of a person, because of difficulties in intellectual and adaptive functioning (Burack, 2012). Students with intellectual disabilities (SWID) face problems with memory, generalisation, conceptual skills, low motivation, social-emotional skills (Haegele \& Park, 2016), self-confidence (Lee et al., 2009), speaking, logical thinking, and solving problems (Räty, Kontu \& Pirttimaa, 2016). These characteristics thus have an influence on the learning of SWID and require the provision of appropriate education.

SWID have the same rights as students without disabilities, and in particular a right to suitable educational services (Dickson, 2013). One way to guarantee this right is through the provision of an appropriate curriculum. The curriculum, defined as the content of teaching or the knowledge and skills driving pedagogy and evaluation in instruction (Giroux, 1994) is an essential component in special education for SWID.

Al-Zboon (2013) reports that a curriculum for SWID includes numerous components, including, firstly, individual educational planning (IEP) which is pivotal to special education planning (Nilsen \& Herlofsen, 2012). It is evident that SWID have unique abilities and their needs, interests, strengths and preferences differ (Wehmeyer, 2006). The IEP design is one of the most significant tools for guaranteeing effective teaching, learning and enhanced SWID performance (Thompson, Thurlow, Qunemoen, Esler, \& Whetstone, 2001). IEP is considered a vital element in achieving accessibility for SWID to the general curriculum (GC) and supporting the educational progress of SWID (Coyne et al., 2012).

The second component is the general curriculum (GC), developed specifically for children without disabilities (Giangreco, 2017). Plessis and Ewing (2017) determine that teachers should focus on rational adjustments to the curriculum in order that it be individualised and inclusive. SWIDs, as individuals, experience difficulties in accessing the GC, due to inflexible teaching practices (Shurr \& Bouck, 2013). Teachers need a high level of professionalism to be able to differentiate their instruction practice sufficiently to increase SWID accessibility to the GC at the appropriate year levels (Plessis \& Ewing 2017). Although accessibility to the GC has been questioned by some researchers (e.g. Ayres, Lowrey, Douglas, \& Sievers, 2011), the aim is that high expectations will help improve the poor outcomes for SWID, including those with the most severe ID (IDEA, 2004).

The third component is the expanded core curriculum (ECC) for SWID, which contains core areas not covered by GC, such as assistive technology (AT), self-determination (SD) skills and independence skills. This component is an important resource for IEP team members when developing educational plans (Al-Zboon, 2013).

Shurr \& Bouck (2013) report that available research on the SWID curriculum primarily emphasised functional life skills, with a recent growth in investigating cognitive academic content. The functional curriculum emphasises the requirements of the life of SWID, and activities that are of immediate use in the students' future (McGuire, 2001).

Increasing academic content is in line with the shift to accessing the GC, and highlights the emergent philosophical split between functional life skills and general academic content (Ayres et al., 2011). Saad et al. (2015) indicate a high probability of mastering this content if SWID are provided with materials of interest to them throughout the learning process. Shurr and Bouck (2013) indicate that recent literature emphasises academic subjects (arithmetic, science, social studies, reading, writing and spelling).

Alkhateeb et al. (2012) report that the SWID curriculum should include the following: academic skills (i.e. reading, writing, mathematics), daily life skills, vocational skills, communication skills, motion skills and social -emotional skills. Additionally, Algahtani (2017) reports these skills: independent living, handling money, time management, community engagement and vocational skills. Rose, McDonnell \& Ellis (2007) cite recreational activities and physical activity as curriculum components of SWID. Additionally, nowadays inclusion is one of the the primary topics of curricular content (Shurr and Bouck, 2013).

Modern literature emphasises self-determination (SD) as a component of the SWID curriculum (e.g., Al Hazmi, \& Ahmad, 2018) in order to access the GC, as it is vital that SWID develop the ability to make decisions and choices that will enhance their overall quality of life and well-being. Alyazori (2017) reported that the SWID curriculum could be improved by harmonising content 
and student mental and performance levels; allocating time in the lesson schedule based on significance of the content; and considering the coherence between the contents of the subjects horizontally and vertically.

The literature documents problems in areas of the curriculum fields and in teachers' training needs. Teachers of SWID need to gain the competences necessary to evaluate students' intellectual level in order to adapt their teaching tactics appropriately (Lamport, Graves \& Ward, 2012). They face significant difficulties in areas of the curriculum such as preparing IEP and goals, while teacher training needs include current trends in the SWID curriculum and teaching methods (Alyazori, 2017).

McBride \& Al-Khateeb (2010) report that teachers of SWID do not receive adequate training in the curriculum as part of their training programme, and engage in education without sufficient training to teach SWID. Giles (2009) observes that one of the most imperative training areas for teachers is curriculum-related competence.

A systematic review by Shurr and Bouck (2013) indicate a lack of research literature focused on the curriculum for SWID, despite an increasing academic interest in this topic. For example, Alyazori (2017) reports that the SWID curriculum has a low priority in the Arab world, resulting in a lack of resources and funding. The curriculum is weak, as it does not follow scientific basics or evidence-based practices, and faces further problems, such as a lack of teachers' guidebooks and publications that would increase the ability of teachers to teach SWID. Al-Zboon (2016b) reveals confusion concerning the curriculum for SWID, which needs a comprehensive reform. Additionally, research reveals problems in support services, such as physical and occupational therapy (Al-Qreny, 2007) and AT to facilitate implementation of the curriculum (Al-Zboon, 2019; Al-Zboon, 2020). Plessis \& Ewing (2017) report that making rational modifications to a SWID programme is considered a constant, complex and continual effort throughout the instruction process. Coyne (2012) reveals that the main issue regarding the SWID curriculum is the selection of contents based on student-specific learning and intellectual ability (Coyne et al., 2012).

One study reports that increased SD among SWID leads to considerable improvements in academic and transition outcomes and in access to the GC (Shogren, Palmer, Wehmeyer, Williams-Diehm \& Little, 2012).
Alkhateeb et al. (2012) reveal that the availability of SWID programmes of international standards in Jordan is low in the areas of family involvement, and inclusion and transition services. Coyne et al. (2012) reveal that SWID teachers evaluate content as the area in which they have least competence.

Al-Zboon (2016a) defines a set of curriculum components for students with disability (SWD): general and specific outcomes documentation, student textbooks, teacher textbooks and supported learning resources. Dababneh, Al-Zboon \& Akour (2016) show that the most central teaching competency needing improvement is the development of instructional planning strategies. Al-Zboon (2015) recommends the development of a professional team to re-evaluate the curriculum for SWD.

In Jordan, the "Education Reform for the Knowledge Economy" was launched (Al-Zboon, 2016c), which focuses on reforming elements of Jordanian education, and in particular the curriculum. However, this reform process focuses on the GC, with no consideration of SWID. In 2013, MOE adapted curriculum outcome documents to be suitable for students with hearing impairments from kindergarten to fourth grade. Unfortunately, this process was not completed for other disability categories such as ID.

In 2018, the National Council for Curriculum (NCC) was founded, to improve the curriculum in line with the international contemporary practices, and the country's educational philosophy and needs.

Services for SWD in Jordan come in many different forms, including separate and inclusion programmes managed by the MOE, Community Based Rehabilitation (CBR) programmes, and day and residential centres managed by the Ministry of Social Development and the private sector (Ministry of Education (MOE), 2014).

The Jordanian Law on the Rights of the Persons with Disabilities of 2017 states that all residential institutions must close within ten years, and all related institutions should integrate their strategies and plans to guarantee inclusion of SWD (HCD, 2007). Furthermore, the 10year Inclusive Education Strategy was launched in January 2020 to facilitate inclusion. This reforming environment in Jordan has raised the importance of the SWID curriculum in preparation for an inclusive era. 
Further research regarding the SWID curriculum is necessary in order to continue to provide high quality opportunities and education for SWID. There is a lack of qualitative studies in the field of the curriculum (Shurr \& Bouck, 2013); consequently, this study aims to investigate the current state of the SWID curriculum in Jordan through the perceptions of special education teachers and field observations.

\section{METHOD}

\section{Participants}

A purposive sample was adopted in the current study, and 54 (18 male and 36 female) teachers of SWID were purposively selected from day centres for SWID in Zarqa Conversance, Jordan. The educational level of the participants varied, some having attained a two-year diploma $(\mathrm{n}=14)$, bachelor's degree $(\mathrm{n}=37)$, and master's degree $(n=3)$. Participants' teaching experience ranged from 3 to 16 years.

\section{Ethical considerations}

Ethical approval was obtained from the Institutional Review Board (IRB) at Hashemite University, Jordan. Ethical principles considered in conducting this study included gaining official permission, and informed consent from the participants. All participants volunteered to participate and pseudonyms were allocated to each of them to ensure confidentiality.

\section{Data collection}

Two qualitative techniques were used for data collection. First, semi-structured interviews were conducted. Creswell (2009) reported that the interview is a vital technique in collecting data on informants' opinions, beliefs and perceptions regarding a studied phenomenon. Interview protocols were prepared and the interviews conducted at a time of the teachers' choice in the SWID day centres. All interviews were tape-recorded and lasted between 30 and 50 minutes. Secondly, field observations were carried out by watching classes of SWID, to observe practices related to the curriculum, such as its content, learning resources and daily routine.

\section{Data analysis}

To gain in-depth meaning from interview data and observations, a three-stage thematic analysis was used. First, the general themes were identified by an overview of the raw data; secondly, theme-categories were identified by reviewing the documents; and thirdly, miscoded passages were checked by re-reading the data documents to review the evidence.

\section{Credibility}

Certain activities are considered to increase the trustworthiness of the results (Stommel \& Wills, 2004). In the current study, credibility was increased firstly by the triangulation of multiple methods for collecting data (e.g. interviews, field observation, literature review); secondly, by interview-related procedures (e.g. interviewer training, constructing the interview process in advance, listening to all the interview recordings, and ensuring that the interviewers had produced the transcripts reliably); and thirdly, by using peer researchers as a method of member checking.

\section{RESULTS}

\section{Teachers' perceptions of curriculum areas}

Data analysis revealed that SE teachers identified 14 curriculum areas for SWID: daily life skills $(n=31)$; reading and writing $(\mathrm{n}=28)$; mathematical skills $(\mathrm{n}=26)$; perceptual skills $(\mathrm{n}=21)$; language skills $(\mathrm{n}=17)$; self-appreciations $(\mathrm{n}=16)$; motor skills, mainly fine motor skills $(\mathrm{n}=16)$; vocational skills $(\mathrm{n}=12)$; religious principles $(\mathrm{n}=3)$; science $(\mathrm{n}=2)$; inclusion preparation skills $(\mathrm{n}=2)$; English language $(\mathrm{n}=2)$; music $(\mathrm{n}=1)$; drama $(\mathrm{n}=1)$; sensory skills $(\mathrm{n}=1)$. Huna said, "the daily life skills are the most important domain as they lead to increase independence. The second important skill is Arabic language skills, i.e. reading and writing."

\section{Teachers' perceptions of curriculum characteristics}

When asked about the characteristics of a SWID curriculum, most participants identified that the curriculum should be easy, simple, sequential, harmonised with the child's abilities, needs, interests and desires, rich in pictures and colours and focused on pre-reading skills, pre-writing skills, pre-math skills, functional and independence skills. Most teachers reported the lack of using the curriculum to student empowerment and preparing students for inclusion. Shadi said, "curriculum must be easy and simple, our centres follow CPL form and when students achieve all form goals then we implement KG curriculum." 


\section{Levels of teacher professional competences and their training needs}

Data analysis revealed that most SE teachers perceived themselves as having an acceptable level of professional knowledge in terms of curriculum. However, the data analysis demonstrated confusion among teachers in some curriculum issues. When asked about the curriculum used with SWID, the majority of teachers saw textbooks as the curriculum. Ahmed said, "Do you mean textbooks? We don't have specific textbooks." Additionally, they were unfamiliar with the ECC concept: 18 participants responded, "I don't know". When asked about IEP and IIP, many teachers responded that they used them. Classroom observations revealed confusion in curriculum practices, as most teachers depend on teacher-made worksheets or on student notebooks to write questions to be answered by the student. Many teachers depend on a form to identify specific tasks and skills for all students. Some MOE general text books exist for first, second and third classes which are used by teachers in some cases. Teachers experience difficulty in using the IEP and IIP as they are not based on nor implemented in reality and there is no effective collaboration between the IEP team. In many cases, design and implementation of the IEP is the responsibility of one teacher alone. There is no effective family involvement in the development of the IEP, and many centres do not have IEP team professionals, such as physical therapists, occupational therapists and communication therapists. The majority of SE centres does not use AT in curriculum implementation.

Additionally, data analysis of interviews and field observations revealed that teachers have multiple training needs with regard to the curriculum, including current trends in curriculum; designing individual plans based on modern international practices; using teaching aids to implement the curriculum in the classroom; modifying the curriculum based on individual differences; using the curriculum to prepare children for inclusion and child empowerment; choosing appropriate curriculum content for every SWID; using AT in the implementation of the curriculum; curriculum-based evaluation; and collaboration between the multidisciplinary team to implement the curriculum. Suha said, "I feel that I need training in designing a curriculum suitable for every student based on modern practices. Unfortunately, I have used the same worksheets and forms since 5 years."

\section{Teachers' perceptions \\ of the problems of curriculum implementation}

Participants indicated that they face many problems hindering the effective implementation of the SWID curriculum, including the lack of availability of strong evaluation tools to identify current performance levels of students; lack of family involvement in implementation; low expectations from family; lack of communication between family and professionals; incorrect diagnosis and classification of student disability; lack of materials and tools; difficulties in multidisciplinary team work; lack of funding; administration; resistance of teachers to new ideas and practices: lack of experience in using AT; heterogeneity among SWID, restricting teachers with specific contents to be applied; lack of student readiness to learn due to lack of early intervention programmes; lack of teacher competence in curriculum, designing learning aids, class management and behaviour modification; lack of effectiveness of teachers' pre- and inservice preparation programmes; students' behavioural and emotional problems; and problems in the physical environment. The following excerpts exemplify participants' sentiments on these issues.

Jamal said:

"I have many goals and ideas to implement with my students but I can't implement them effectively because of low available resources, material and AT."

Lama indicated:

"There isn't any support from family as they exclude themselves from the training process or have low expectations."

\section{Curriculum components}

Data analysis revealed that participants reported the following as components of the SWID curriculum: work sheets $(\mathrm{n}=26)$; student's notebook $(\mathrm{n}=25)$; IEP $(\mathrm{n}=24)$; IIP ( $n=24)$; CPL form $(n=18)$; attached learning resources (such as picture cards, alphabet and number boards, games, blocks, story series) (15); regular curriculum for kindergarten $(n=8)$; teacher textbook $(n=6)$; regular curriculum for the first three primary classes $(n=4)$; student textbook $(n=3)$, font notebook $(n=2)$.

The majority of participants indicated "random" items as part of the curriculum, whereby "random" refers to teachers' personal work: there are no specific textbo- 
oks for teachers or students, and any books used will be the teacher's choice, as textbooks are not considered a basic part of the curriculum. Additionally, the majority of teachers considered a set of work-sheets made by teachers as a SWID curriculum.

Some teachers mentioned the existence of Current Performance Level (CPL) forms that teachers use as a general framework for the curriculum. This form is distributed to special education centres by the Ministry of Social Development. These teachers mentioned that they use the KG curriculum after achieving the targets on the CPL form.

The majority of participants were unsure how to define the ECC for SWID, and had a limited awareness of the ECC components. However, the field observations revealed the existence of some practices related to ECC components, such as training in independence skills, low technology tools, and some social skills.

Content analysis and field observations revealed some confusion in curriculum practices and issues as there is no general framework document, reference book or teacher guidebook to help in designing or delivering the curriculum, or identifying the curriculum areas and goals.

Some teachers reported the importance of having a special comprehensive curriculum for SWID.

\section{DISCUSSION}

This study employed a qualitative method to highlight the current status of the SWID curriculum. It finds that there is widespread confusion, and that the problem of a curriculum for SWID in Jordan has not been given sufficient attention. According to the perceptions of the study sample, the SWID curriculum should include many elements. The most frequently mentioned were daily life skills, reading, writing and mathematical skills, in line with worldwide studies showing the importance of these areas (e.g., Al Khateeb et al., 2012). Perceptual skills were cited with moderate frequency, and those areas mentioned less frequently included language skills, self -appreciation, motor skills (mainly fine motor skills) and vocational skills. Unfortunately, the elements cited least frequently were religious principles, science, music, inclusion preparation skills, English language, drama and sensory skills. These findings indicate that the SWID programmes in Jordan focus only on basic academic subjects (reading, writing and mathematics). This is not in line with related literature (e.g. Algahtani, 2017; Epps, 2016), which highlights the non-academic elements as bringing important skills to the SWID curriculum. Giangreco (2017) reports that teachers should ensure the provision of directive instructions in numerous skill domains as well as in the GC to manage the deficiencies in intellectual functioning and adaptive behaviours.

Additionally, these findings do not align with modern literature that focuses on access to the whole curriculum, not only reading, writing and mathematics (e.g. ABrowder et al., 2007). However, the emphasis on increased academic content aligns, and is consistent, with the changed focus on access to the GC, and highlights the emergent philosophical split between functional life skills and general academics (Ayres et al., 2011). Teachers of SWID do therefore require strong competences to differentiate their teaching practice to increase SWID accessibility to the GC at appropriate year levels (Plessis \& Ewing, 2017). Saad et al. (2015) emphasise languages, sciences and social studies as SWID curriculum components.

Inclusion is also one of the curriculum areas mentioned with least frequency, despite being considered nowadays a priority in SWID education, and one of the primary topics of curricular content (Shurr \& Bouck, 2013). Additionally, these findings highlight the absence of other vital areas, such as SD, which is mentioned in current literature on the curriculum (Shogren, Palmer, Wehmeyer, Williams-Diehm \& Little, 2012; Wehmeyer $\&$ Schalock, 2001). Jimenez et al. (2012) reported that increased SD among SWID leads to considerable improvements in academic and transition outcomes, and in access to the GC for SWID. Furthermore, another component missing from the participants' responses is AT, which is an important curriculum component (Al-Zboon, 2019). However, this is in line with many studies (e.g. Al-Zboon, 2019; Al-Zboon, 2020; Jimenez, Graf $\&$ Rose, 2007).

This state of confusion and concern regarding the SWID curriculum in Jordan could be explained by many reasons. First, the non-classification teachers' preparation programme is dominant in Jordan, which affects the competencies of teachers in the education of SWID. Secondly, topics such as access to the GC, inclusion, 
$\mathrm{SD}$, AT have only recently gained popularity worldwide. Thirdly, the separated model of SWID education is common in Jordan, which affects the curriculum situation. However, Jordan recently launched its 10-year Inclusive Education Strategy, so it may be expected that the status of education of SWID will change in line with current trends for inclusion. The importance of the current research appears therefore to lie in highlighting the importance of the SWID curriculum, increasing the access of these students to the GC and improving their SD to prepare them for inclusion.

Results reveal some indications of low expectations of SWID on the part of teachers. First, teachers described the characteristics of the SWID curriculum as easy and simple. Secondly, they reported sometimes using MOE general text books (especially Arabic language and mathematics textbooks) for first to third classes with SWID. Thirdly, some teachers mentioned that they used the KG curriculum after achieving the elements on the CPL form. These low expectations are mentioned in the literature and considered to be factors preventing the progress of SWID (McGrew \& Evans, 2003). They indicate a risk, as these expectations are from teachers who are responsible for the programme's implementation. There is therefore a vital need to enhance teachers' expectations and raise their awareness regarding the ability of SWID, in order to increase the students' access to GC, the level of their performance and their preparation for inclusion. These low expectations should be considered especially in the light of the previous results which indicated confusion among teachers over some curriculum issues. However, this result is not consistent with the findings of Dababneh et al. (2016), who revealed that teachers do not think that they need to develop their competence in the area of attitudes and expectations of SWD.

In the current study, some confusion and low levels of teachers' professionalism regarding the curriculum are evident in a number of areas. Firstly, teachers consider textbooks themselves to be the curriculum (which contradicts the commonly approved view in the field that the textbook is only one component of the curriculum). Secondly, many participants are unfamiliar with the ECC concept. Thirdly, there is a random element in the curriculum as teachers devise their own resources and worksheets, and use student notebooks or standard forms to identify specific tasks and skills for all students. Fourthly, there are no general framework documents, reference books or teacher guidebooks to help in designing or delivering the curriculum, or in identifying the curriculum content and goals. Al-Zboon (2016a) describes a collection of proposed curriculum components for SWD (e.g. a general framework and outcomes document; textbooks for children, textbooks for teachers; and associated learning resources).

All previous results documented on curriculum issues echo previous studies. Alyazori (2017) reveal that teachers evaluate content as of least importance in SWID programmes and programmes for SWID are weak as they do not follow scientific basics or evidence-based practice. These findings are similar to those of previous studies related to the curriculum for SWD in Jordan, which have also reported this confusion. For example, Al-Zboon (2015; 2016b) reveals confusion regarding the curriculum for students with disability and the need for a comprehensive reform process. Al-Zboon (2015) recommends the development of a professional team to review the curriculum for SWID. This result could be explained by Jimenez, Graf, \& Rose's (2007) findings that the disability institutions do not receive sufficient funding to provide instruction tools and adapt the learning environment, especially as in the Arab world SWID programmes have not been seen as a priority, due to lack of resources and funding (Alyazori, 2017).

The results revealed many issues of concern regarding IEP. Firstly, a large number of centres do not have all the IEP team specialists, such as physical therapy, occupational therapy and communication therapy. Secondly, teachers experience difficulties in using the IEP and IIP as these are not based on reality. Thirdly, there is a lack of effective collaboration between the IEP team, as usually the IEP design and implementation is the responsibility only of the teacher. Fourthly, there is no effective family involvement in IEP development process and, fifthly, many teachers do not recognise the IEP and IIP as components of the SWID curriculum. These results are frustrating as IEP is considered a vital requirement in achieving access for SWID to the GC and in supporting the educational progress of SWID (Coyne et al., 2012). However, a number of previous studies reveal the same results: Al-Qreny (2007) reports that physical and occupational therapy are the services least supported in SWID centres in Saudi Arabia. Dababneh, et al., (2016) reveal that teachers report problems with team working. Additionally, al-Shamari \& Hornby (2020) found a number of issues with teachers' competences and practices in IEP. 
In addition, data analysis of interviews and field observations revealed that teachers have significant training needs related to the curriculum: current trends in curriculum, designing individual plans based on modern international practices, using teaching aids in delivery of the curriculum, modifying the curriculum based on individual differences, using the curriculum to prepare child for inclusion and child empowerment, selecting appropriate curriculum content for each SWID, using AT to deliver the curriculum, curriculum based evaluation, and collaboration between the multidisciplinary team to implement the curriculum.

This finding is supported by the related literature which reported the importance of in-service training programmes to meet teachers' training needs. Alyazori (2017) reports such needs as IEP design, especially goal writing, and current trends in curriculum and modern teaching methods while Dababneh et al. (2016) report instructional planning strategies, communication skills, assessment, managing the classroom environment and team working.

Participants indicated that they face a number of problems hindering the effective implementation of the curriculum with SWID. These problems are related to evaluation and diagnosis, poor family involvement, lack of materials, lack of tools and funding, multidisciplinary team work, administration issues, SWID characteristics, lack of teacher competencies and problems with the physical environment.

However, other studies concur with Alyazori (2017) who found that there is a lack of available guides and publications which are important in increasing the ability of teachers to teach SWID, a lack of tests to identify ID and a failure to respond to the outcomes of evaluation to make conclusions about SWIDs' learning (Plessis \& Ewing, 2017) as evaluation enhances the effectiveness of educational programmes for SWID. Jimenez, Graf $\&$ Rose ( 2007) report that educational alternatives are not prepared with the necessary tools and services to address the individual needs of the SWID (Jimenez, Graf $\&$ Rose, 2007). Alkhateeb et al. (2012) reveal that, by international standards, SWID programmes in Jordan are low in the areas of family involvement, inclusion, and transition services. Coyne et al. (2012) observe problems in the selection of contents, teaching methods, and teachers' competencies (Coyne et al., 2012) while Plessis $\&$ Ewing (2017) determine that making rational modifi- cations to a SWID programme (through the instruction process) is a constant, complex and continual process so problems may be encountered if stakeholders are not aware of the merits of the SWID curriculum.

Another important issue arising from the current study is the teachers' responses about components of SWID curriculum, with the most frequently cited examples being work sheets, student's notebook, IEP, IIP; examples cited moderately frequently being the CPL form, associated learning resources (such as pictures cards, alphabet and number boards, games, blocks, story series), regular curriculum for kindergarten. Finally, the components mentioned least often are teacher textbook, regular curriculum for the first three primary classes, student textbook, Font Notebook.

This finding is unsatisfactory as many teachers lack a comprehensive outlook on curriculum components. This highlights the importance of professional development programmes for teachers regarding curriculum and, more importantly, the need for all stakeholders (e.g. teachers, the principal, curriculum developer, decision-makers) to adopt a shared outlook regarding the curriculum. However, teachers' competencies reflect their own experiences gained from their work environment, the national environment and preparation programmes which do not provide experience of a curriculum model for SWID. There is therefore evidence that the reform process should be carried out at the level of the centres, the teachers' preparation programmes and the national level.

\section{RECOMMENDATIONS}

\section{Based on the results of the current study,}

there is an urgent need to improve the status of the SWID curriculum as a priority, primarily by enhancing teachers' professionalism and practices, as well as by developing curriculum-related documents such as a guide for teachers of ID, providing guidelines for instruction, reference books, general principles for teachers, theoretical knowledge about this disability, basic glossaries in the field and a document of the general and specific outcomes for SWID. The data support the importance of developing targeted curricula that include specialised areas for SWID, such as independence skills, functional academic skills, self-determination, AT skills and emotional-social skills. 
In this era of inclusion, there is a vital need to focus on inclusion preparation, self-determination and more advanced academic skills, not just on daily life skills, reading, writing and mathematics. Additionally, there is a need to raise awareness regarding real expectations from SWID and to end the stigma and the stereotype that SWID have to be taught an easy, simple curriculum.

\section{CONCLUSION}

The current study helps gauge the status of the SWID curriculum in Jordan. The results indicate confusion in the field of SWID education, which is dependent on teachers' personal efforts with no foundation of evidence-based practices or shared outlook between stakeholders regarding the curriculum. Teachers depend on worksheets, and there is no effective use of AT, and inadequate funding and resources. There is no effective team-working in designing IEP due to a lack of available multidisciplinary professionals and family involvement. There are real problems in accessing the GC for SWID, and also in preparation for inclusion, improving SD and using AT. Teachers have low expectations regarding SWID. However, the findings of this study should be read cautiously as they depend on qualitative methods alone. There is a need for further studies to clarify the picture of the SWID curriculum using other methods and techniques, by investigating the problem from the perspective of other stakeholders, such as families, specialists, principles and the students themselves.

\section{ACKNOWLEDGEMENT}

None.

\section{DISCLOSURE STATEMENT}

No potential conflict of interest

was reported by the authors.

FUNDING: None.

\section{REFERENCES}

Al Hazmi, N. \& Ahmad A. (2018). Universal Design for Learning to Support Access to the General Education Curriculum for Students with Intellectual Disabilities. World Journal of Education, 8(2).

Alkhateeb, A. (2012). Evaluation of programs and services in institutions for intellectual disabilities based on international standards. International Specializes Educational Journal, 1(3).

Alyazori, M. (2017). Evaluating the programme provided to mental handicapped children in Gaza city as viewed by teachers. Journal of scientific research in education, 18, 347-369.

Al-Zboon, E. (2019). Assistive Technologies as a Curriculum Component in Jordan: Future Special Education Teachers' Preparation and the Field Status. Assistive Technology Journal, DOI: 10.1080/10400435.2019.1677804

Al-Zboon, E. (2020). Perceptions of Assistive Technologies by teachers of Students with Visual Impairments in Jordan. Journal of Visual Impairment \& Blindness.

Al-Zboon, E. (2016a). Kindergarten curriculum for children with hearing impairments: Jordanian teachers' perspectives. Deafness \& Education International, 18(1).

Al-Zboon, E. (2016b). Current state of the curriculum in Jordanian kindergartens for children with hearing impairments. Early Child Development and Care. http://dx.doi.org/10.1080/03004430.2016.1230737.

Al-Zboon, E. (2016c). Special Education Teachers Leadership in Jordan: Current State and Constraints. Societies, 6(3), 1-17.

Al-Zboon, E. (2013). Current Trends and Issues in special education, Dar Al-Fiker, Jordan.

Al-Zboon, E. (2015). An Evaluation of the National Interactive Kindergarten Curriculum and the Document of the General Framework and the General and Specific Outcomes for the Kindergarten Curriculum of Children with Hearing Impairments from Their Teachers' Perspectives: A Qualitative Study. Jordan Journal of Educational Sciences (JJES), 11(3), 387-402. 
Ayres, K. M., Lowrey, K. A., Douglas, K. H., \& Sievers, C. (2011). I can identify Saturn but I can't brush my teeth: What happens when the curricular focus for students with severe disabilities shifts. Education and Training in Autism and Developmental Disabilities, 46, 11-21.

Burack, J. A. (2012). The Oxford handbook of intellectual disability and development. Oxford: Oxford Library of Psychology.

Creswell, J. (2007). Qualitative Inquiry \& Research Design: Choosing Among Five Approaches (2nd ed.). Thousand Oaks, CA, USA: Sage.

Creswell, J., \& D. Miller. (2000). Determining Validity in Qualitative Inquiry. Theory into Practice, 39(3), $124-131$.

Coyne, P., Pisha, B., Dalton, B., Zeph, L. A., \& Smith, N. C. (2012). Literacy by design: A universal design for learning approach for students with significant intellectual disabilities. Remedial and Special Education, 33(3), 162-172.

Dababneh, K., Al-Zboon, E., \& Akour, M. (2016). Competencies that Teachers Need for Teaching Children Who Are Deaf and Hard-of-Hearing $(\mathrm{DHH})$ in Jordan. Deafness \& Education International, DOl: 10.1080/14643154.2016.1249173

Dickson, E. (2013). Disability standards for education and reasonable adjustment in the tertiary education sector. Available: http://www.anzela.edu.au/assets/anzjle_vol_12.2_-_2_dickson.pdf

Epps TS (2016). Special Education Teachers' Lived Experiences in the Implementation of the iPad as an Instructional Tool for Students with Intellectual Disabilities. ProQuest LLC. https://eric.ed.gov/?id=ED571761

Giangreco MF (2017). Expanding opportunities for students with intellectual disability. Education Leadership, 74(7),52-57.

Giles, E. (2009). A phenomenon logical Study of Paraprofessionals Perceptions of Training and Efficacy. Doctoral Dissertation, University of Phoenix.

Giroux, H. A. (1994). Teachers, public life, and curriculum reform. Peabody Journal of Education, 69(3), 35-47.

Haegele JA, \& Park SY (2016). Utilizing generalization tactics to promote leisure- time physical activity for students with intellectual disabilities. Strateg. J. Phys. Sport Educators, 29(4),19-23.

Higher Council for Affairs of Persons with Disabilities (HCD) 2007). Rights of People with Disabilities Act No. (31) of 2007. Available at: http://hcd.gov.jo/ar/node/275

Individuals with Disabilities Education Act (IDEA) of 2004, P.L. 108-44.

Jimenez, T. C., Graf, V. L., \& Rose, E. (2007). Gaining access to general education: The promise of universal design for learning. Issues in Teacher Education, 16(2), 41-54.

Jimenez, B., Browder, D., Spooner, F., \& DiBiase, W. (2012). Inclusive inquiry science using peer-mediated embedded instruction for students with moderate intellectual disability. Exceptional Children, 78, 301-317

McBride, A. \& Al-Khateeb, J. (2010). Policy Options of Special Education in Jordan, Final Report prepared for the Ministry of Education, The Hashemite Kingdome of Jordan. ERfKE 11 Project (Component 4-3).

McGrew, K. \& Evans J. (2004). Expectations for Students with Cognitive Disabilities: Is the Cup Half Empty or Half Full? Can the Cup Flow Over? Minneapolis, MN: University of Minnesota, National Center on Educational Outcomes.

McGuire, L. (2001) Creating Opportunities for Students with Intellectual and Multiple Disabilities. Saskatchewan learning special education unit: Saskatchewan, Canada

Ministry of Education (MOE). (2014). Ministry of Education's Projects in Jordan; MOE: Amman, Jordan.

Nilsen, S., \& Herlofsen, C. (2012). National regulations and guidelines and the local follow-up in the chain of actions in special education. International Journal of Special Education, 27(2), 136-147.

Plessis, J., \& Ewing, B. (2017). Reasonable Adjustments in Learning Programs: Teaching Length, Mass and Capacity to Students with Intellectual Disability. Universal Journal of Educational Research, 5(10), 1795-1805.

Räty, L. M., Kontu, E. K., \& Pirttimaa, R. A. (2016). Teaching children with intellectual disabilities: Analysis of research-based recommendations. Journal of Education and Learning, 5(2), 318.

Rose, T. E., McDonnell, J., \& Ellis, G. (2007) The impact of teacher beliefs on the provision of leisure and physical activity education curriculum decisions. Teacher Education and Special Education, 30(3), 183.

Saad, S., Dandashi A., Aljaam JM, \& Saleh, M. (2015). The multimedia based learning system improved cognitive skills and motivation of disabled children with a very high rate. J. Educ. Technol. Soc., 18(2),366-379.

Shogren, K. A., Palmer, S. B., Wehmeyer, M. L., Williams-Diehm, K., \& Little, T. D. (2012). Effect of intervention with the Self-Determined Learning Model of Instruction on access and goal attainment. Remedial and Special Education, 33, 320-330.

Shurr Jordan \& Bouck Emily (2013). Research on Curriculum for Students with Moderate and Severe Intellectual Disability: A Systematic Review. Education and Training in Autism and Developmental Disabilities, 48(1), 76-87

Stommel, M., \& Wills, C. (2004). Clinical Research: Concepts and Principles for Advanced Practice Nurses. London: Lippincott Williams \& Wilkins.

Thompson, S., Thurlow, M., Qunemoen, R., Esler, A., \& Whetstone, P. (2001). Addressing standards and assessments on state IEP forms (Synthesis report 38). Minneapolis: University of Minnesota, National Center on Educational Outcomes. 